\title{
Salts and Co-crystals of Theobromine and their phase transformations in water
}

\author{
PALASH SANPHUI and ASHWINI NANGIA* \\ School of Chemistry, University of Hyderabad, Prof. C. R. Rao Road, Gachibowli, Central University P.O., \\ Hyderabad 500 046, India \\ e-mail: ashwini.nangia@gmail.com
}

MS received 15 August 2014; accepted 22 August 2014

\begin{abstract}
Theobromine, a xanthine derivative analogous to caffeine and theophylline, is an effective central nervous system stimulant. It has lower aqueous solubility than caffeine and theophylline. Salts of theobromine with hydrochloric acid, phosphoric acid, methanesulfonic acid, benzenesulfonic acid and $p$-toluenesulfonic acid were prepared using liquid-assisted grinding (LAG). Proton transfer from the strong acid to the weak base imidazole $\mathrm{N}$ resulted in $\mathrm{N}^{+}-\mathrm{H} \cdots \mathrm{O}^{-}$hydrogen-bonded supramolecular assemblies of theobromine salts. The mesylate salt is polymorphic with amide $\mathrm{N}-\mathrm{H} \cdots \mathrm{O}$ dimer and catemer synthons for the theobromine cations. A variable stoichiometry for phosphate salts (1:3 and 1:2.5) were observed with the latter being more stable. All new salts were characterized by FT-IR, PXRD, DSC and finally single crystal X-ray diffraction. In terms of stability, these salts transformed to theobromine within $1 \mathrm{~h}$ of dissolution in water. Remarkably, the besylate and tosylate salts are 88 and 58 times more soluble than theobromine, but they dissociated within $1 \mathrm{~h}$. In contrast, theobromine co-crystals with gallic acid, anthranilic acid and 5-chlorosalicylic acid were found to be stable for more than $24 \mathrm{~h}$ in the aqueous slurry conditions, except malonic co-crystal which transformed to theobromine within $1 \mathrm{~h}$. Water mediated phase transformation of theobromine salts and co-crystal may be due to the incongruency (high solubility difference) between the components. These results suggest that even though traditional salts are highly soluble compared to co-crystals, co-crystals can be superior in terms of stability.
\end{abstract}

Keywords. Co-crystal; dissolution; phase transformation; salts; solubility; stability; synthon.

\section{Introduction}

The absorption rates of many poorly aqueous soluble drugs which are hydrophobic and have high $\log \mathrm{P}$ values are limited by poor dissolution rate and low solubility. ${ }^{1}$ Low solubility limits bioavailability leading to dose to dose variation, poorly controlled pharmacological effects, and high dosage resulting in side effects, etc. Over two-thirds of newly discovered drugs currently in the development pipeline face a solubility challenge. Several solubilization methods such as salt formation, particle size reduction, amorphous materials, solid dispersions, lipid-based self-emulsifying systems, etc., are employed to enhance the dissolution rates of the poor soluble APIs. ${ }^{2}$ The most preferred approach to improve the solubility and dissolution rate of ionizable APIs containing acidic/basic functional groups is salt formation. Salts are the first-choice option in the pharmaceutical industry because of their high solubility, excellent stability, ease of crystallization and manufacturing, and formulation as tablets. Over half the APIs are marketed

*For correspondence as salts. ${ }^{3}$ Moreover, salts can modulate other physicochemical properties such as melting point, hygroscopicity, bioavailability, chemical stability, permeability, $\mathrm{p} K_{a}$ (dissociation constant), acute oral toxicity, and overall drug perfomance. ${ }^{4}$ Occasionally it is found that the high solubility salts transform to the low soluble API due to solvent mediated phase transformation ${ }^{5}$ during the dissolution experiments. Such phase transformations depend on several factors such as solvent, $\mathrm{pH}$, surfactants, temperature, and solubility of the coformer. The pharmaceutical chemist has to exercise multiple criteria in selecting the optimal solid form of an API with desirable physicochemical properties.

Theobromine $^{6}$ (TBR, scheme 1) is a bitter alkaloid of the cacao plant. It is the main ingredient in chocolate and also present in a number of other foods, including the leaves of the tea plant, and the kola (or cola) nut. TBR is structurally similar to other xanthine alkaloids such as caffeine (CAF), theophylline (TPH) but less soluble $(330 \mathrm{mg} / \mathrm{L}$; CAF $21.6 \mathrm{~g} / \mathrm{L}$, TPH 7.4 $\mathrm{g} / \mathrm{L})$. Consistent with its low solubility, it has higher M.p. $\left(357^{\circ} \mathrm{C}\right)$ compared to $\mathrm{CAF}\left(238^{\circ} \mathrm{C}\right)$ and $\mathrm{TPH}$ $\left(272^{\circ} \mathrm{C}\right)$. TBR has a similar, but lesser effect compared 
<smiles>Cn1c(=O)c2c(ncn2C)n(C)c1=O</smiles>

Caffeine (CAF)<smiles>Cn1c(=O)c2[nH]cnc2n(C)c1=O</smiles>

Theophylline (TPH)<smiles>Cn1cnc2c1c(=O)[nH]c(=O)n2C</smiles>

Theobromine (TBR)
Scheme 1. Chemical structure of xanthine analogues.

to CAF in the human nervous system. ${ }^{6 \mathrm{~b}, \mathrm{c}}$ Lee et al. $^{6 \mathrm{~d}}$ reported that TBR exhibits anti-carcinogenic activity (especially liver cancer) in US patent 2003/0099686A1. Unlike the well-known hydration problem of caffeine and theophylline, ${ }^{6 e, f}$ theobromine is stable in anhydrous form even after $24 \mathrm{~h}$ in water slurry. Hence co-crystals and/or salts are possible opportunities to improve the solubility of theobromine.

The acid/base profile of a compound has a direct effect on the lipophilicity of that substance as governed by the ionization constants ( $\mathrm{p} K_{a}$ values) of the functional groups. TBR is a weak base $\left(\mathrm{p} K_{a}=10.0\right)$ similar to CAF $\left(\mathrm{p} K_{a}=10.4\right)$ and $\mathrm{TPH}\left(\mathrm{p} K_{a}=\right.$ 8.8). Co-crystals of TBR with several acids such as acetic acid, malonic acid, 5-chlorosalicylic acid, trifluoroacetic acid, gallic acid, anthranilic acid, quercetine and salts with perchloric acid are reported in the literature. ${ }^{7}$ Weaker carboxylic acids form co-crystals and stronger acids form salts of TBR. There are no reports on co-crystals/salts of TBR with the objective to modulate its solubility and stability. Keeping in mind that strong acids will make salts with TBR, hydrochloric acid $\left(\mathrm{p} K_{a}=-7.7\right.$, very strong acid), methanesulfonic acid ( $\mathrm{p} K_{a}=-1.9$, strong acid), phosphoric acid $\left(\mathrm{p} K_{a}=2.2,7.2,12.4\right.$, strong to moderate acid), and pharmaceutically acceptable acids such as benzenesulfonic acid $\left(\mathrm{p} K_{a}=-2.8\right)$ and $p$-toluenesulfonic acid $\left(\mathrm{p} K_{a}=-2.8\right)$ are discussed in this study. Proton transfer from the acid to the imidazole $\mathrm{N}$ of TBR confirms the ionic nature of the salt (scheme 2). All pharmaceutical salts were characterized by IR, PXRD, DSC, and single crystal $\mathrm{x}$-ray diffraction, as described in a few cases from our group (e.g., clofazimine, etravirine, aceclofenac). ${ }^{4 \mathrm{f}, 8}$ TBR was studied to make a novel solid<smiles></smiles>

Scheme 2. Protonation of imidazole nitrogen in the presence of strong acid to give TBR salts. oral dosage form with improved solubility and stability profile.

\section{Experimental}

TBR and other co-formers were purchased from SigmaAldrich (Hyderabad, India) and used directly for experiments. All other chemicals were of analytical or chromatographic grade. M.p. was measured on a Fisher-Johns' M.p. apparatus. Water filtered through a double deionized purification system (AquaDM, Bhanu, Hyderabad, India) was used in all experiments.

\subsection{Theobromine hydrochloride salt monohydrate $\left(\mathrm{TBRH}^{+} \mathrm{Cl}^{-} . \mathrm{H}_{2} \mathrm{O}, 1: 1: 1\right)$}

Single crystals were obtained from crystallization in conc. $\mathrm{HCl} .100 \mathrm{mg}$ theobromine was dissolved in $5 \mathrm{~mL}$ conc. $\mathrm{HCl}$ after mild heat and then kept for crystallization. After 1 week colourless rectangular thick plate crystals were obtained from $\mathrm{HCl}$ solution. Bulk amount can be obtained from direct $\mathrm{MeOH}$ assisted grinding in presence of 1-2 $\mathrm{mL}$ of Conc. $\mathrm{HCl}$. M.p. $170-172^{\circ} \mathrm{C}$.

\subsection{Theobromine phosphate salts $\left(\mathrm{TBRH}^{+}(\mathrm{PHP})_{3}^{-}\right.$ and $\left.\mathrm{TBRH}^{+}(\mathrm{PHP})_{2.5}^{-}\right)$}

Single crystals were obtained from conc. $\mathrm{H}_{3} \mathrm{PO}_{4}$ at RT. $100 \mathrm{mg}$ theobromine was dissolved in $5 \mathrm{~mL}$ conc. $\mathrm{H}_{3} \mathrm{PO}_{4}$ after mild heat and then kept for crystallization. After 4 days, colourless block crystals $\left(\mathrm{TBR}^{+}(\mathrm{PHP})_{3}^{-}\right)$ were obtained. After 1 week, block crystals disappeared and thick rod crystals $\left(\mathrm{TBRH}^{+}(\mathrm{PHP})_{2.5}^{-}\right)$harvested at expense of the former. Bulk amounts of $\left(\mathrm{TBRH}^{+}(\mathrm{PHP})_{2.5}^{-}\right)$could be obtained directly from $\mathrm{MeOH}$ assisted grinding in presence of $1-2 \mathrm{~mL}$ of conc. $\mathrm{H}_{3} \mathrm{PO}_{4}$. $\mathrm{TBRH}^{+}(\mathrm{PHP})_{3}^{-}$was difficult to reproduce because of its metastable nature. M.p. $130-132^{\circ} \mathrm{C}$ $\left(\mathrm{TBRH}^{+}(\mathrm{PHP})_{2.5}^{-}\right)$.

\subsection{Theobromine mesylate salt polymorphs $\left(T B R H^{+} M E S^{-}(1: 1)\right.$ form I \& II)}

Single crystals were obtained from conc. methanesulfonic acid at RT. $100 \mathrm{mg}$ theobromine was dissolved in $5 \mathrm{~mL}$ conc. $\mathrm{MeSO}_{3} \mathrm{H}$ after mild heat and then kept for crystallization. After 2 days, colourless square plate crystals $\left(\mathrm{TBRH}^{+} \mathrm{MES}^{-}\right.$form I) were obtained. After 1 week, metastable form I crystals disappeared and thick plate crystals $\left(\mathrm{TBRH}^{+} \mathrm{MES}^{-}\right.$form II) appeared at the expense of the former. Bulk amount $\left(\mathrm{TBRH}^{+} \mathrm{MES}^{-}\right.$ form II) could be obtained from direct $\mathrm{MeOH}$ assisted 
grinding in presence of $1-2 \mathrm{~mL}$ of conc. $\mathrm{MeSO}_{3} \mathrm{H}$. We were unable to reproduce crystallization of metastable form I of theobromine mesylate. M.p. $216-218^{\circ} \mathrm{C}$ $\left(\mathrm{TBRH}^{+} \mathrm{MES}^{-}\right.$form II).

\subsection{Theobromine besylate salt $\left(\mathrm{TBRH}^{+} B E \mathrm{~S}^{-}, 1: 1\right)$}

$100 \mathrm{mg}(0.55 \mathrm{mmol})$ theobromine and $87.8 \mathrm{mg}(0.55$ mmol) benzenesulfonic acid was dissolved in $10 \mathrm{~mL}$ $\mathrm{MeOH}$ after mild heat and then kept for crystallization. After 2-3 days colourless rectangular thick plate crystals were obtained at RT. Bulk amount can be obtained from direct $\mathrm{MeOH}$ assisted grinding of equimolar amount of both components. M.p. 284-286 ${ }^{\circ} \mathrm{C}$.

\subsection{Theobromine tosylate salt $\left(\mathrm{TBRH}^{+} \mathrm{TOS}^{-}, 1: 1\right)$}

$100 \mathrm{mg}(0.55 \mathrm{mmol}) \mathrm{TBR}$ and $95.6 \mathrm{mg}(0.55 \mathrm{mmol})$ $p$-toluenesulfonic acid was dissolved in $10 \mathrm{~mL} \mathrm{MeOH}$ after mild heat and then kept for crystallization. After 2-3 days, colourless rectangular thick plate crystals were obtained. Bulk amount can be obtained from direct $\mathrm{MeOH}$ assisted grinding of equimolar amount of both components. M.p. $275-277^{\circ} \mathrm{C}$.

TBR co-crystals with malonic acid, anthranilic acid, gallic acid and 5-chlorosalyclic acids were prepared according to the literature procedure ${ }^{7}$ and confirmed their uniqueness by PXRD comparison (figure S1).

\section{$2.6 \quad X$-ray crystallography}

Single crystal obtained from the crystallization solvent(s) was mounted on the goniometer of Oxford Gemini (Oxford Diffraction, Yarnton, Oxford, UK) equipped with Mo-K $\alpha$ radiation $(\lambda=0.71073 \AA)$ source. Data reduction was performed using CrysAlisPro 171.33 .55 software. ${ }^{23}$ Crystal structures were solved and refined using Olex2-1.0 ${ }^{24}$ with anisotropic displacement parameters for non-H atoms. Hydrogen atoms were experimentally located through the Fourier difference electron density maps in all the crystal structures. All aromatic $\mathrm{C}-\mathrm{H}$ atoms were geometrically fixed using HFIX command in SHELX-TL program of Bruker-AXS. ${ }^{25}$ A check of the final .cif file with PLATON $^{26}$ did not show any missed symmetry. XSeed $^{27}$ was used to prepare the figures and packing diagrams. Crystallographic parameters of crystal structures are summarized in table 1 . Hydrogen bond distances in table $\mathrm{S} 1$ are neutron-normalized to fix the $\mathrm{D}-\mathrm{H}$ distance to its accurate neutron value in the x-ray crystal structures (N-H $0.82 \AA, \mathrm{C}-\mathrm{H} 1.083 \AA$ ).

\subsection{Powder $x$-ray diffraction}

Bulk samples were analyzed by Powder x-ray diffraction with a Bruker AXS D8 powder diffractometer (Bruker-AXS, Karlsruhe, Germany). Experimental conditions: $\mathrm{Cu}-\mathrm{K} \alpha$ radiation $(\lambda=1.54056 \AA)$; $40 \mathrm{kV} ; 30$ $\mathrm{mA}$; scanning interval $5-40^{\circ} 2 \theta$ at a scan rate of $1 \%$ min; time per step $0.5 \mathrm{~s}$. The experimental PXRD patterns and calculated X-ray lines from crystal structures were compared to confirm purity of the bulk phase using Powder Cell. ${ }^{28}$

\subsection{Thermal analysis}

DSC was performed on a Mettler Toledo DSC 822e module. Samples were placed in crimped, but vented aluminum sample pans for DSC. The temperature range was $30-350^{\circ} \mathrm{C}$ at $5^{\circ} \mathrm{C} / \mathrm{min}$ for DSC. The samples (4-6 mg) were purged with a stream of dry $\mathrm{N}_{2}$ flowing at $150 \mathrm{~mL} / \mathrm{min}$.

\subsection{Vibrational spectroscopy}

A Thermo-Nicolet 6700 FT-IR spectrometer (Waltham, MA, USA) was used to record IR spectra on samples dispersed in $\mathrm{KBr}$ pellets.

\section{Results and Discussion}

Due to weak basicity ( $\mathrm{p} K_{a}=10.0$ ), TBR is able to make salts with strong acids only. There are reports on perchlorate salts ${ }^{7 \mathrm{e}}$ of CAF, TPH and TBR, in which the imidazole nitrogen is protonated (scheme 2). Theobromine salts were crystallized with 1:1 stoichiometry except hydrochloride and phosphate, which gave a hydrochloride salt hydrate $(1: 1: 1$ with $\mathrm{HCl})$ a metastable phosphate (1:3) and stable (1:2.5 with $\mathrm{H}_{3} \mathrm{PO}_{4}$ ) theobromine phosphate salt (table 1 for crystallographic parameters). In the crystal structure of TBR (REFCODE-SEDNEQ, Z' = 2), ${ }^{9}$ two molecules in the asymmetric unit form a carboxamide dimer through $\mathrm{N}-$ $\mathrm{H} \cdots \mathrm{O}$ hydrogen bonds (figure 1). There is no report on polymorphs of TBR, unlike e.g., CAF and TPH. ${ }^{10}$ A polymorphic crystal structure with $\mathrm{Z}^{\prime}=1^{11}$ or $\mathrm{N}$ $\mathrm{H} \cdots \mathrm{O}$ with the other $\mathrm{C}=\mathrm{O}$ group of imide is not reported for TBR so far. Several crystallization attempts with different solvents/mixtures, sublimation, and melt cooling did not afford a new form. The crystal structures of $\mathrm{AcOH}$, trifluroacetic acid and malonic acid adducts of TBR were solved by powder XRD data. ${ }^{7 \mathrm{~b}, \mathrm{c}}$ All the salts were prepared by solvent crystallization to give single crystals suitable for $\mathrm{x}$-ray diffraction. 


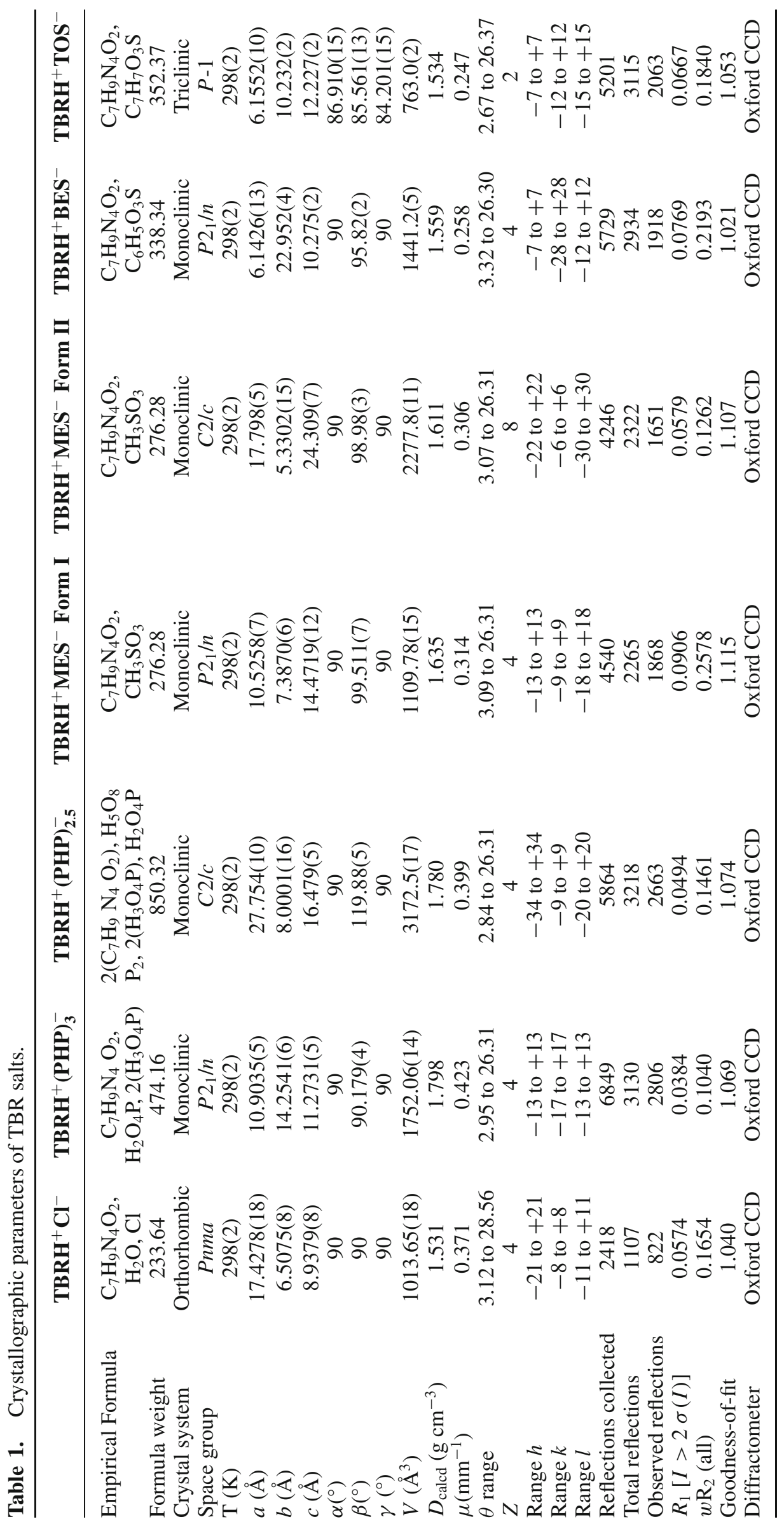




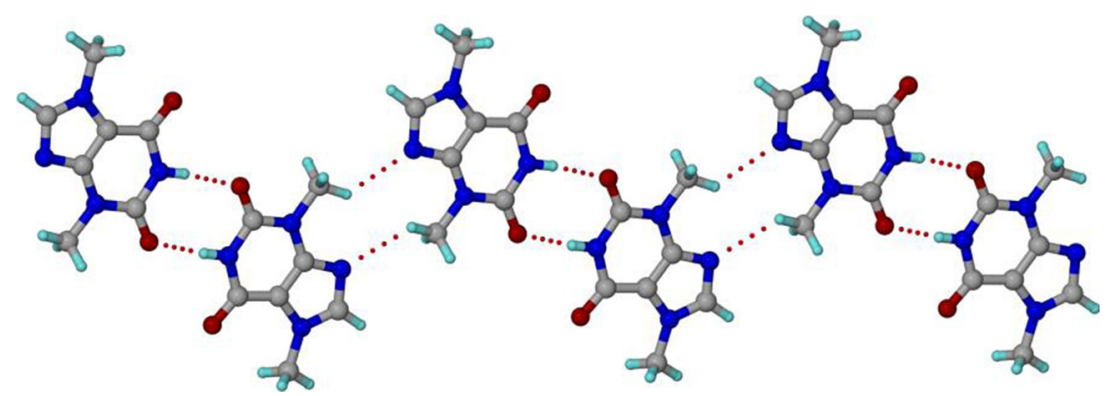

Figure 1. $\mathrm{N}-\mathrm{H} \cdots \mathrm{O}$ and $\mathrm{C}-\mathrm{H} \cdots \mathrm{N}$ hydrogen bonded dimers form a $1 \mathrm{D}$ chain in TBR. Symmetry-independent TBR molecules are involved in carboxamide dimer synthon.

\subsection{Theobromine hydrochloride salt monohydrate $\left(\mathrm{TBRH}^{+} \mathrm{Cl}^{-} . \mathrm{H}_{2} \mathrm{O}, 1: 1: 1\right)$}

Crystallization of TBR from dilute $\mathrm{HCl}$ gave hydrochloride salt monohydrate. The crystal structure was solved in orthorhombic space group Pnma with one each of $\mathrm{TBRH}^{+}, \mathrm{Cl}^{-}$and water molecule in the asymmetric unit. Hydrochloric acid is strong enough to protonate the imidazole nitrogen $(\mathrm{N} 2-\mathrm{H} 2 \cdots \mathrm{Cl} 1,2.04$ $\AA, 178^{\circ}$ ) and disrupts the carboxamide $\mathrm{N}-\mathrm{H} \cdots \mathrm{O}$ dimer of TBR, similar to that in $\mathrm{TBRH}^{+} \mathrm{ClO}_{4}^{-}$salt. ${ }^{7 \mathrm{e}}$ The chloride ion acts as a bridge between two theobromine cations (N4-H4. $\mathrm{Cl} 11,2.15 \AA, 174^{\circ}$ ) via a 1D chain (figure $2 \mathrm{a}$ ), which are connected to water through $\mathrm{O}_{-}$ $\mathrm{H} \cdots \mathrm{O}$ and $\mathrm{O}-\mathrm{H}^{\cdots} \mathrm{Cl}^{-} \mathrm{H}$-bonds to give a layer structure parallel to $a c$ plane. Parallel chains of $\mathrm{TBR}^{+} \mathrm{Cl}^{-} \cdot \mathrm{H}_{2} \mathrm{O}$ arrange in a layer motif viewed down the $c$-axis at $\pi \cdots \pi$ distance of $3.32 \AA$ (figure $2 b$ ).

\subsection{Theobromine phosphate salts $\left(\mathrm{TBRH}^{+}\left(\mathrm{H}_{3} \mathrm{PO}_{4}\right)_{x}^{-}, x=3\right.$ and 2.5$)$}

When phosphoric acid $\left(\mathrm{H}_{3} \mathrm{PO}_{4}\right)$ was used to crystallize TBR, a salt of stoichiometry $\mathrm{TBRH}^{+}$ $\left(\mathrm{H}_{3} \mathrm{PO}_{4}\right)_{2}\left(\mathrm{H}_{2} \mathrm{PO}_{4}^{-}\right)$was obtained initially and at the end of the reaction a more stable phosphate salt $\mathrm{TBRH}^{+}\left(\mathrm{H}_{3} \mathrm{PO}_{4}\right)\left(\mathrm{H}_{2} \mathrm{PO}_{4}^{-}\right)_{0.5}\left(\mathrm{H}_{5} \mathrm{P}_{2} \mathrm{O}_{8}^{-}\right)_{0.5}$ was isolated with the disappearance of the first salt. The metastable salt $\mathrm{TBRH}^{+}(\mathrm{PHP})_{3}^{-}(1: 3)$ could not be reproduced in later experiments (disappearing form). ${ }^{12}$

The crystal structure of $\mathrm{TBRH}^{+}(\mathrm{PHP})_{3}^{-}$(1:3) was solved in monoclinic space group $P 2_{1} / n$ with one $\mathrm{TBRH}^{+}$, one phosphate anion $\left(\mathrm{H}_{2} \mathrm{PO}_{4}^{-}\right)$and two neutral phosphoric acid in the asymmetric unit (figure 3a). A proton is transferred from one phosphoric acid to TBR imidazole nitrogen confirming its salt nature. Inversion related $\mathrm{TBRH}^{+}$cations form a carboxamide dimer (figure $3 \mathrm{~b}$ ). There is an alternate layer of $\mathrm{TBRH}^{+}$(hydrophobic region) and phosphoric acid (hydrophilic region) viewed down the crystallographic $b$-axis (figure $3 \mathrm{c}$ ). Surprisingly, there are no strong interactions between $\mathrm{TBRH}^{+}$and $\mathrm{PHP}^{-}$; instead layers of $\mathrm{TBRH}^{+}$and phosphoric acid (neutral) molecules interact through auxiliary $\mathrm{O}-\mathrm{H} \cdots \pi(\mathrm{O} \cdots \pi: 3.01 \AA)$ and $\mathrm{C}-\mathrm{H} \cdots \mathrm{O}(\mathrm{C} \cdots \mathrm{O}: 2.627 \AA)$ interactions, which explains the instability of this salt. $\mathrm{TBRH}^{+}$forms a layer structure through $\mathrm{N}-\mathrm{H} \cdots \mathrm{O}(\mathrm{N} 1-\mathrm{H} 1 \cdots \mathrm{O} 1,1.99$ $\left.\AA, 160^{\circ}\right)$ and $\mathrm{C}-\mathrm{H} \cdots \mathrm{O}\left(\mathrm{C} 5-\mathrm{H} 5 \cdots \mathrm{O} 1,2.31 \AA, 158^{\circ}\right)$ hydrogen bonds, suggesting that a second polymorph is possible for this structure. Two equivalent monophosphate anions form centrosymmetric dimer of $\mathrm{O}-\mathrm{H} \cdots \mathrm{O}$ hydrogen bonds $\left(\mathrm{O} 4-\mathrm{H} 4 \cdots \mathrm{O} 6,1.70 \AA, 167^{\circ}\right)$ and the remaining two phosphoric acid molecules connect with the phosphate dimer $(\mathrm{O} 7-\mathrm{H} 7 \cdots \mathrm{O} 5,1.59 \AA, 165 \AA$; $\mathrm{O} 10-\mathrm{H} 10 \cdots \mathrm{O} 12,1.56 \AA, 165^{\circ}$ ) to form a hydrogen bonded 1D chain between the theobromine layers (figure 3d).

Theobromine phosphate salt $\mathrm{TBRH}^{+}(\mathrm{PHP})_{2.5}^{-}(1: 2.5)$ was solved in the $C$-centered monoclinic crystal lattice $(C 2 / c)$ with one $\mathrm{TBRH}^{+}$, half equivalent of phosphate anion, and two neutral phosphoric acids bonded as monoanion in the asymmetric unit (figure 4a). The centrosymmetric carboxamide dimer of $\mathrm{TBRH}^{+}$ions is present. $\mathrm{TBRH}^{+}$ions are surrounded by 10 phosphoric acid/ phosphates to make a cage like structure (figure $4 \mathrm{~b}$ ). Five phosphoric acid molecules including one phosphate anion aggregate through $\mathrm{O}-\mathrm{H} \cdots \mathrm{O} /$ $\mathrm{O}-\mathrm{H} \cdots \mathrm{O}^{-}$hydrogen bonds between two $\mathrm{TBRH}^{+}$ dimers, arranged in a zigzag fashion between layers of phosphoric acid/ phosphate ion (figure $4 \mathrm{c}$ ). A view of the molecular packing and hydrogen bonding in 1:2.5 and 1:3 salts suggests that the former should be more stable because of stronger $\mathrm{O}-\mathrm{H} \cdots \mathrm{O}$ and $\mathrm{N}^{+}-\mathrm{H} \cdots \mathrm{O}$ $\mathrm{H}$-bonds between $\mathrm{TBRH}^{+}$and $\mathrm{PHP}^{-}$in the latter structure whereas weaker interactions hold the former salt structure. The 1:3 phosphate salt being metastable follows the Ostwald's rule of stages in crystallization: ${ }^{13}$ it appeared initially (after 4 days), but finally gave way 


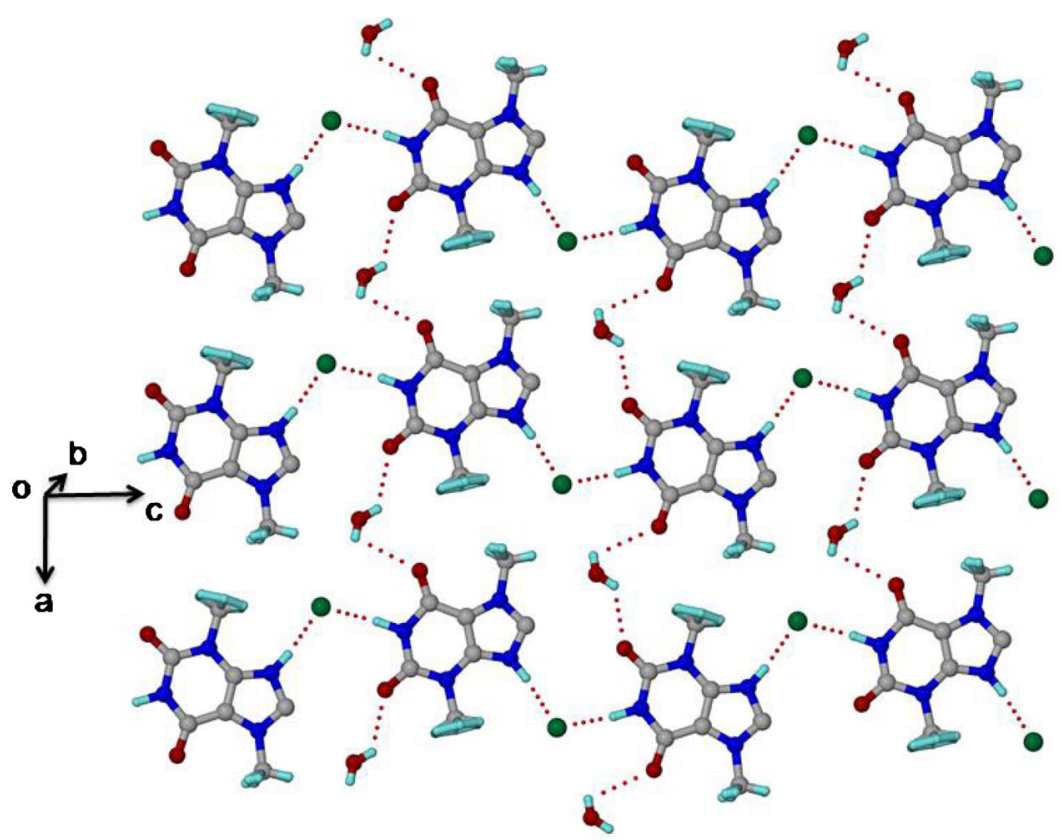

(a)

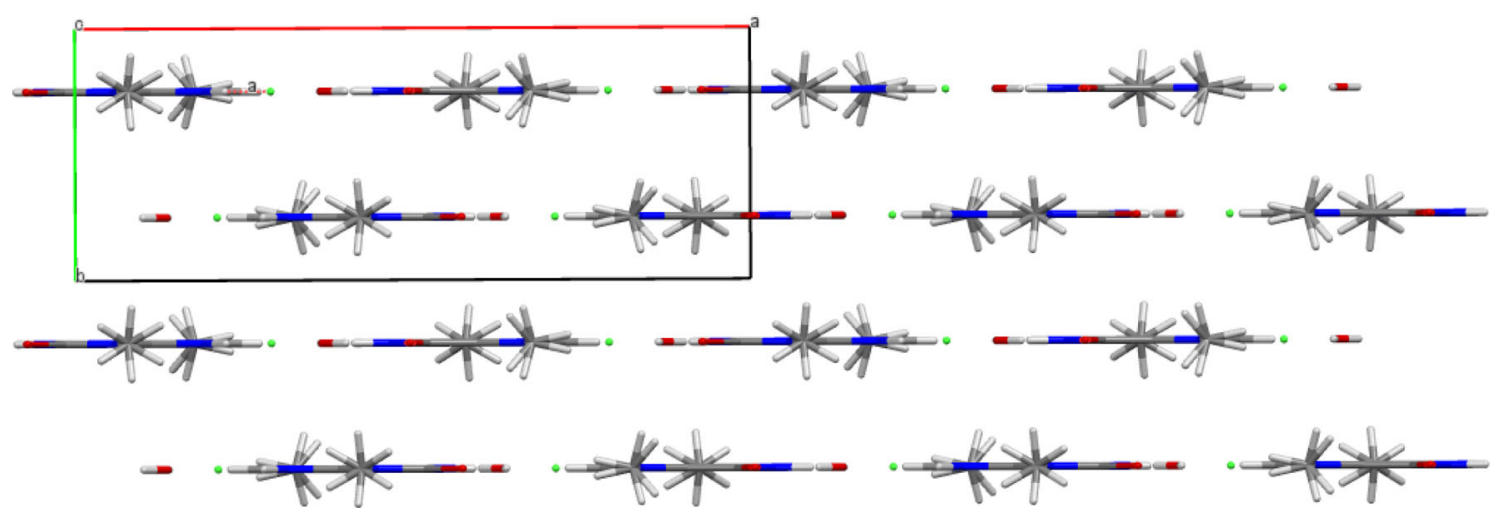

(b)

Figure 2. (a) Packing of $\mathrm{TBRH}^{+} \mathrm{Cl}^{-} \cdot \mathrm{H}_{2} \mathrm{O}$ to show water and $\mathrm{Cl}^{-}$ions in the channel down the $b$ axis. $\mathrm{TBRH}^{+}$molecules are bonded to water and $\mathrm{Cl}^{-}$ions. (b) Parallel chains of molecules are stacked with off-stacked along the $c$-axis.

to the stable $(1: 2.5)$ phosphate salt as the stable product (after 7 days).

\subsection{Theobromine mesylate salt $\left(\mathrm{TBRH}^{+} \mathrm{MES}^{-}, 1: 1\right)$ polymorphs}

Crystallization from methanesulfonic acid gave two polymorphs ${ }^{14}$ of 1:1 stoichiometry. During initial crystallizations, a metastable form appeared and at the end of the experiment a stable form was harvested at the expense of the former. Metastable form I became opaque (may be due to phase transformation) ${ }^{15}$ after one day at ambient conditions, although there was no solvent residue in the crystal lattice. Form I was difficult to reproduce in our hands despite several crystallization attempts under a variety of conditions. The crystal structure of Form I was solved in the monoclinic space group $P 2_{1} / c$. Proton transfer from methanesulfonic acid to TBR confirmed its salt nature in the solid-state. The methyl carbon (s.o.f. 0.6 and 0.4 ) and one oxygen atom (s.o.f 0.6 and 0.4 ) of mesylate are disordered over two positions. $\mathrm{TBRH}^{+}$forms carboxamide dimer via $\mathrm{N}-\mathrm{H} \cdots \mathrm{O}$ hydrogen bonds $\left(\mathrm{N} 1-\mathrm{H} 1 \cdots \mathrm{O} 1,1.95 \AA, 168^{\circ}\right)$ along with ionic H-bonds between $\mathrm{TBRH}^{+}$and $\mathrm{MES}^{-}$in a 1D chain (figure 5a). Two $\mathrm{TBRH}^{+}$and two $\mathrm{MES}^{-}$form tetramer through $\mathrm{N}^{+}-\mathrm{H} \cdots \mathrm{O}^{-}\left(\mathrm{N} 4-\mathrm{H} 4 \cdots \mathrm{O} 3,1.78 \AA, 164^{\circ}\right)$ and $\mathrm{C}-\mathrm{H} \cdots \mathrm{O}\left(\mathrm{C} 4-\mathrm{H} 5 \cdots \mathrm{O} 5,2.19 \AA\right.$ A $\left.149^{\circ}\right)$ H-bonds. 


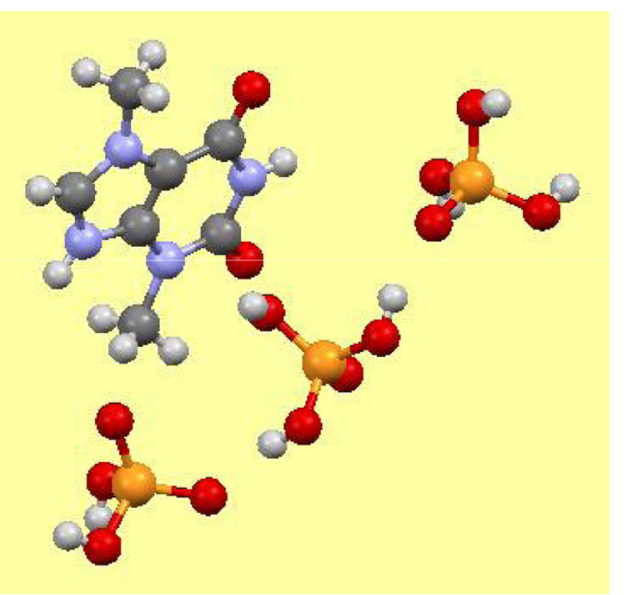

(a)

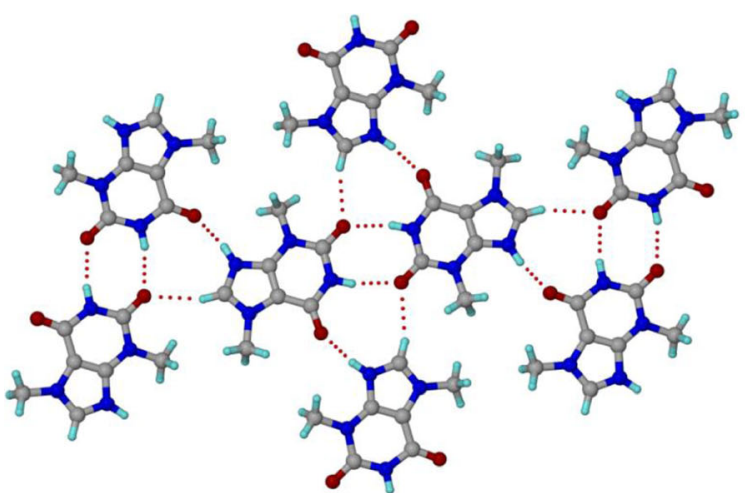

(b)

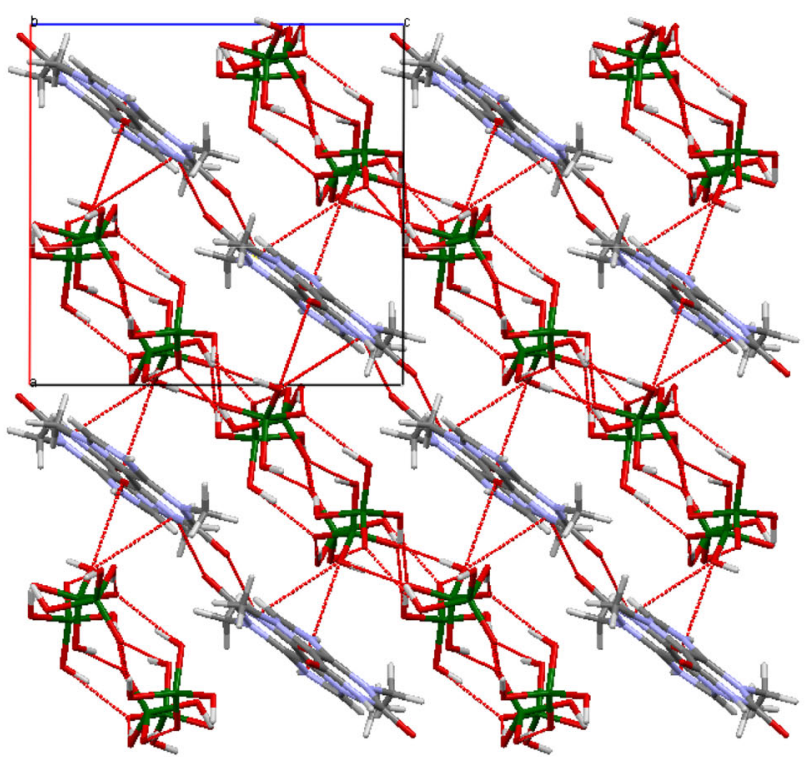

(c)

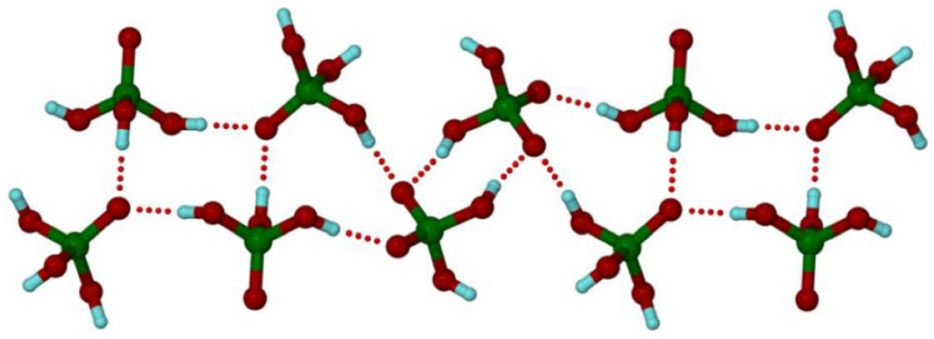

(d)

Figure 3. (a) The asymmetric unit of TBR(PHP) 3 to show one theobromine and two $\mathrm{H}_{3} \mathrm{PO}_{4}$ and one $\mathrm{H}_{2} \mathrm{PO}_{4}^{-}$giving the started stoichiometry of the salt. (b) $\mathrm{N}-\mathrm{H} \cdots \mathrm{O}$ and $\mathrm{C}-\mathrm{H}^{\cdots} \mathrm{O}$ H-bonds between $\mathrm{TBRH}^{+}$cations of $\mathrm{TBRH}^{+}(\mathrm{PHP})_{3}^{-}$salt. (c) Packing diagram of $\mathrm{TBR}^{+}(\mathrm{PHP})_{3}^{-}$viewed down the $b$-axis. The proton is transferred from one phosphoric acid to imidazole $\mathrm{N}$ of TBR. The other two phosphoric acids are neutral. The layers of $\mathrm{TBR}^{+}$and PHP are connected through $\mathrm{C}-\mathrm{H} \cdots \mathrm{O}$ and $\mathrm{O}-\mathrm{H} \cdots \pi$ interactions. (d) Two phosphoric acids $\left(\mathrm{H}_{3} \mathrm{PO}_{4}\right)$ and one phosphate anion $\left(\mathrm{H}_{2} \mathrm{PO}_{4}^{-}\right)$form a $1 \mathrm{D}$ chain of hydrogen bonds in the crystal structure of $\mathrm{TBRH}^{+}(\mathrm{PHP})_{3}^{-}$.

The crystal structure of form II TBR mesylate was solved in monoclinic space group $C 2 / c$. $\mathrm{TBRH}^{+}$ ions form amide catemer synthon through $\mathrm{N}-\mathrm{H} \cdots \mathrm{O}$ hydrogen bonded chains (N1-H1… O1, $1.97 \AA$, $161^{\circ}$; figure $5 b$ ). Mesylate anions interact with $\mathrm{TBRH}^{+}$ catemer via ionic $\mathrm{N}^{+}-\mathrm{H} \cdots \mathrm{O}^{-}$hydrogen bonds (N3-H3 ‥ O 3, $1.63 \AA, 168^{\circ}$ ).

The main difference between the two salt polymorphs is the dimer and catemer hydrogen bonds of $\mathrm{TBRH}^{+}$, a known but not so common case of synthon polymorphs. ${ }^{14 \mathrm{e}, 16}$ Recently, Gratz et al. ${ }^{14 \mathrm{~d}}$ reported synthon polymorphs of sulfoaildenafil mesylate, with the crystal structures having catemer and tetramer arrangements of sulfoaildenafil cations and mesylate anions (sulfoaildenafil is a derivative of the well known sildenafil drug). The packing differences between form I and II of $\mathrm{TBRH}^{+} \mathrm{Mes}^{-}$indicate that theobromine cations and mesylate anions are arranged in ABBA fashion in form I, whereas in form II the alternate arrangement of cations and anions is present (ABAB pattern) (figures $5 \mathrm{c}$ and $5 \mathrm{~d}$ ). In form I, the mesylate ions are $2_{1}$ screw-axis related, whereas in form II they are $c$-glide related. According to the Density rule form I (density $1.635 \mathrm{~g} / \mathrm{cm}^{3}$ ) is more stable than form II (density $1.611 \mathrm{~g} / \mathrm{cm}^{3}$ ). However, we were unable to crystallize form I in bulk quantity and a conclusion about the experimental stability relationship of polymorphs is postponed.

The Cambridge Structural Database (CSD version, 5.35, November 2013, Feb 2014 update $)^{17}$ shows that out of 99 mesylate salts of organic crystal structures, 63 are reported as mesylate salts and 33 are mesylate salt hydrates/solvates. There are only 3 mesylate salts polymorphs in the CSD, e.g., pergolide methanesulfonate 


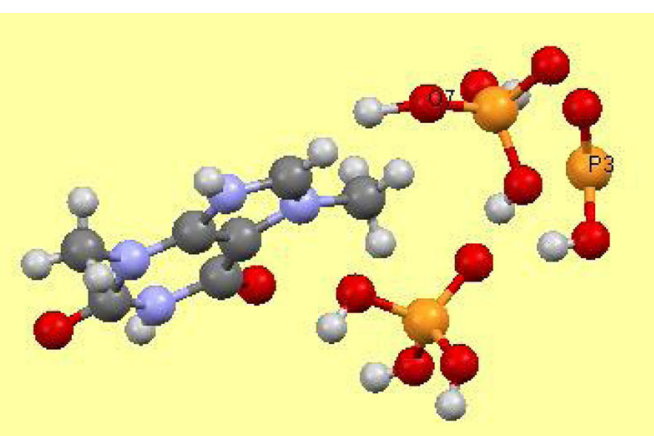

(a)

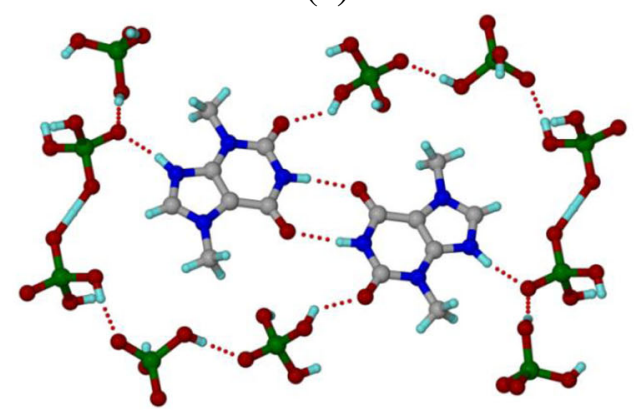

(b)

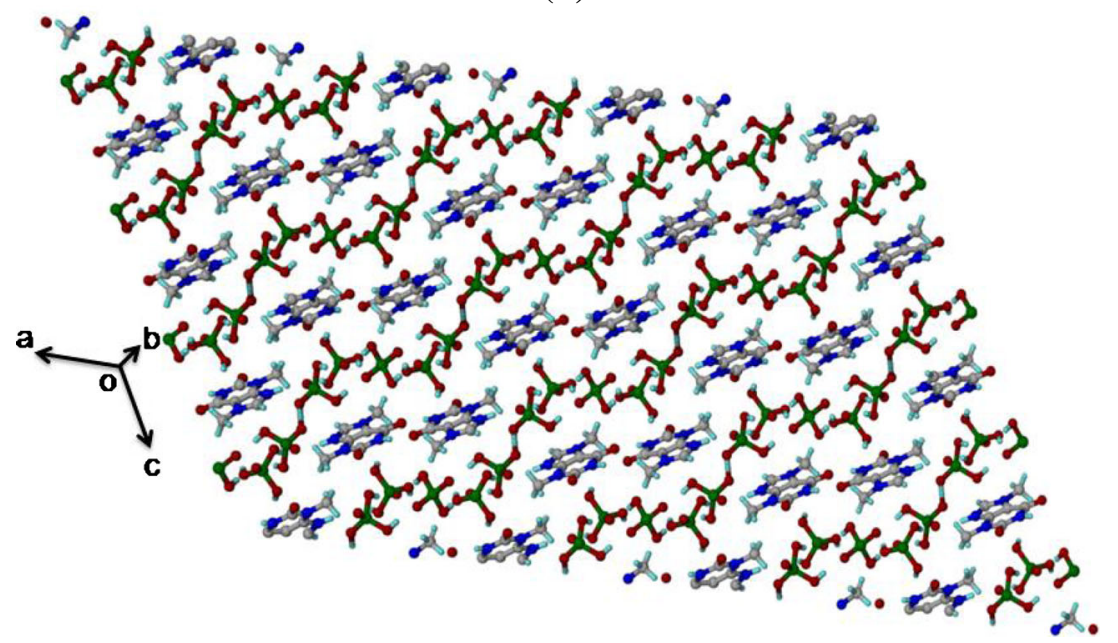

(c)

Figure 4. (a) Asymmetric unit of TBR(PHP $)_{2.5}^{-}$to show one TBR cation, one $\mathrm{H}_{3} \mathrm{PO}_{4}, 0.5 \mathrm{H}_{3} \mathrm{PO}_{4}(\mathrm{P} 4)$ and a $\mathrm{H}_{3} \mathrm{PO}_{4}$ with a shared proton (O7). (b) Hydrogen bonds between $\mathrm{TBRH}^{+}$and phosphate anion and phosphoric acid in the crystal structure of $\mathrm{TBRH}^{+}(\mathrm{PHP})_{2.5}^{-}$salt. (b) The packing diagram of this salt viewed down the $b$-axis. Five phosphate and $\mathrm{H}_{3} \mathrm{PO}_{4}$ molecules aggregate between with $\mathrm{TBRH}^{+}$ions, which confirm the stoichiometry as 1:2.5.

trimorphs (Refcode FIDYIA/01/02), ${ }^{14 \mathrm{a}-\mathrm{c}}$ sulfoaildenafil mesylate dimorphs (Refcode KUMCEB/01), ${ }^{14 \mathrm{~d}}$ and imatinib mesylate dimorphs (Refcode XAVTOF/02). ${ }^{14 \mathrm{e}}$

\subsection{Theobromine besylate salts $\left(\mathrm{TBRH}^{+} \mathrm{BES}^{-}, 1: 1\right)$}

The ionic nature of theobromine besylate $\left(P 2_{1} / n\right.$, $\mathrm{Z}=4$ ) was confirmed from the proton transfer of benzenesulfonic acid to imidazole $\mathrm{N}$ base of TBR. Centrosymmetric carboxamide $\mathrm{N}-\mathrm{H} \cdots \mathrm{O}$ dimer is sustained in the besylate salt, followed by ionic $\mathrm{N}^{+}-\mathrm{H} \cdots \mathrm{O}^{-}$H-bonds between $\mathrm{TBR}^{+}$and $\mathrm{BES}^{-}$ (figure $6 \mathrm{a}$ ). The sheet like structure viewed down $a$ axis in which theobromine dimers are surrounded by six $22_{1}$ screw axis related besylate anions is shown in figure $6 b$. 


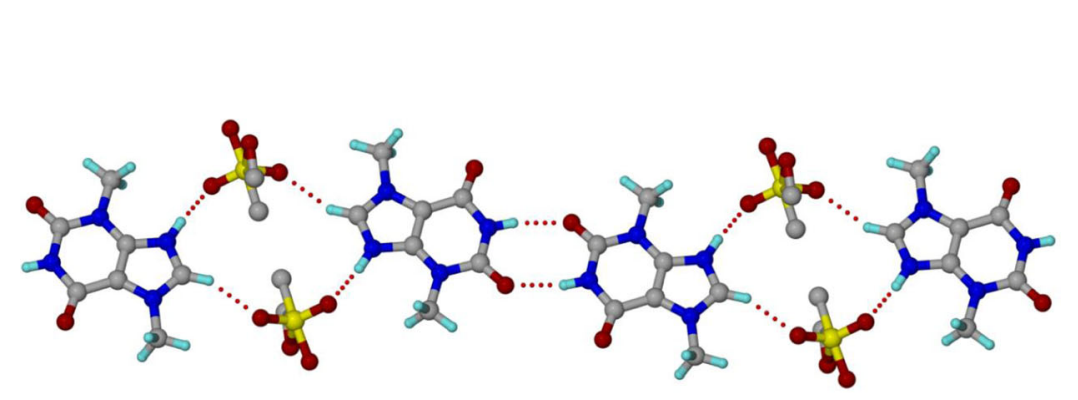

(a)

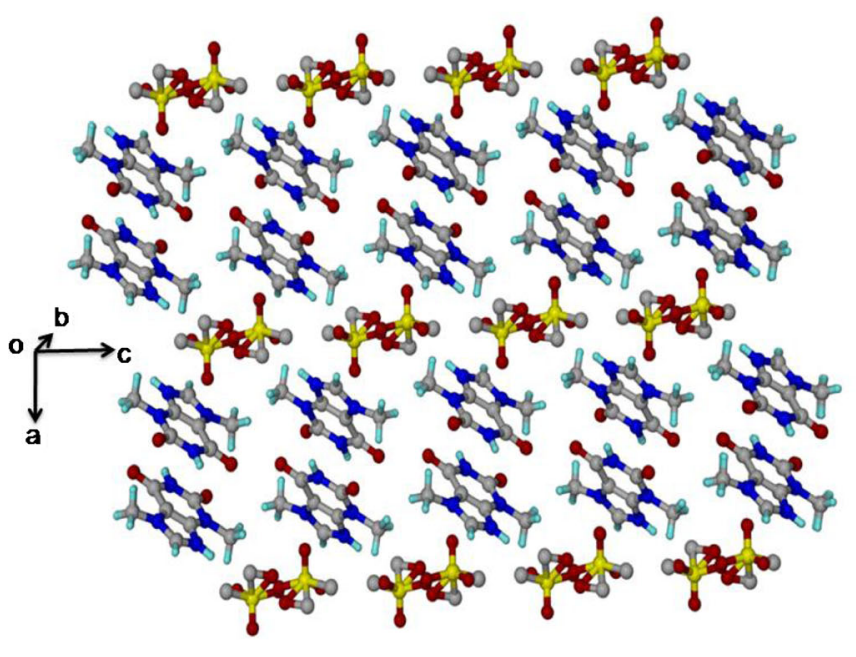

(c)

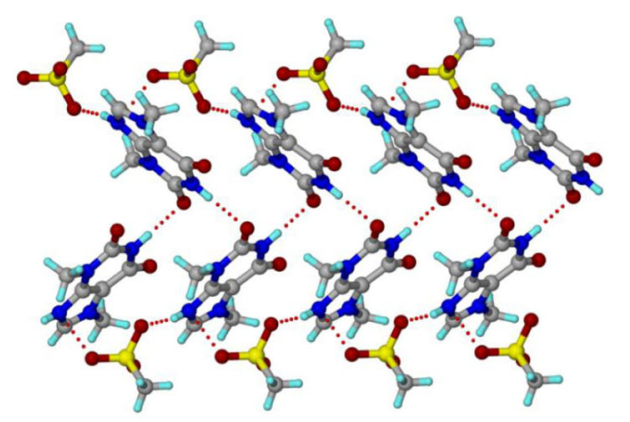

(b)

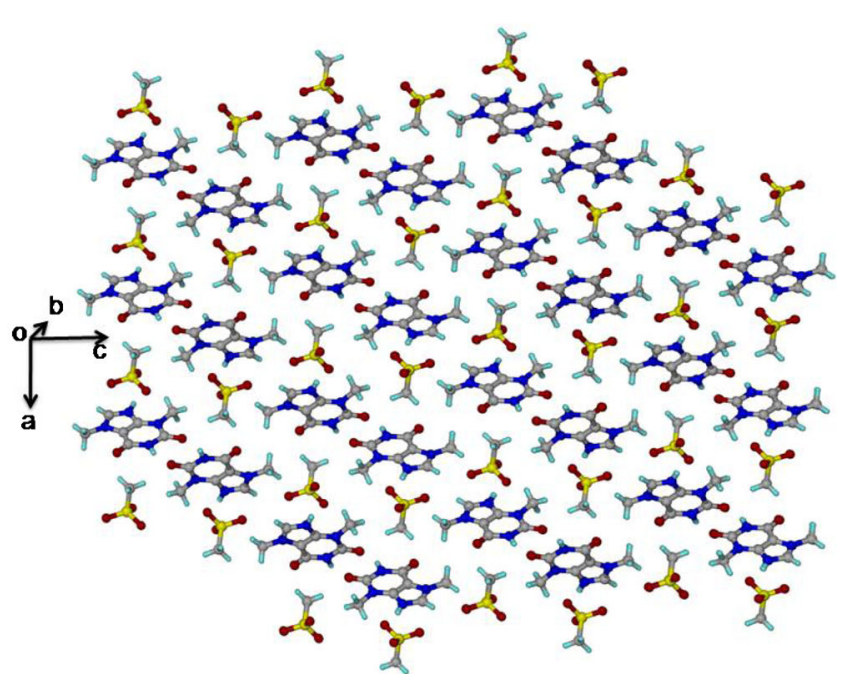

(d)

Figure 5. (a) Centrosymmetric carboxamide $\mathrm{N}-\mathrm{H} \cdots \mathrm{O}$ dimer of $\mathrm{TBRH}^{+}$ions along with ionic $\mathrm{N}^{+}-\mathrm{H} \cdots \mathrm{O}^{-}$between $\mathrm{TBRH}^{+}$and $\mathrm{MES}^{-}$ions in form I. (b) TBRH ${ }^{+}$ions form zigzag hydrogen bonds via $\mathrm{N}-\mathrm{H} \cdots \mathrm{O}$ hydrogen bond catemer between $\mathrm{TBR}^{+}$ions and $\mathrm{N}^{+}-\mathrm{H} \cdots \mathrm{O}^{-}$ionic hydrogen bond between $\mathrm{TBRH}^{+}$and mesylate ions in form II. Crystal packing differences between (c) form I and (d) form II of $\mathrm{TBRH}^{+} \mathrm{MES}^{-}$salts.

\subsection{Theobomine tosylate salt $\left(\mathrm{TBRH}^{+} \mathrm{TOS}^{-}, 1: 1\right)$}

The salt structure $(P-1, \mathrm{Z}=2)$ consists of $\mathrm{TBRH}^{+}$ dimer and ionic H-bonds between $\mathrm{TBRH}^{+}$and $\mathrm{Tos}^{-}$ (figure 7a). The packing in the tosylate salt viewed down the $a$-axis (figure $7 \mathrm{~b}$ ). $\mathrm{TBRH}^{+}$dimers are surrounded by six inversion related tosylate anions, similar to the besylate salt.

Even though TBR is a weak base, it forms salts with several mineral acids such as $\mathrm{HCl}, \mathrm{H}_{3} \mathrm{PO}_{4}$ and also organic acids such as methanesulfonic acid, benzenesulfonic acid and $p$-toluenesulfonic acid. All these salts contain acid-imidazole ionic $\mathrm{H}$-bonds (see scheme 3 and listed in table 2). Except the hydrochloride salt and form II of the mesylate salt, the other salts are consistently sustained by the carboxamide dimer homosynthon of theobromine cations, similar to that in the crystal structure of TBR (figure 1). A summary of all the synthons in these salts and reported co-crystals ${ }^{7}$ is listed in table 2. Generally, in a co-crystal containing carboxylic acid, imidazole and amide functional groups, the imidazole-acid heterosynthon (stronger) is preferred over the acid-amide motif (less strong). ${ }^{18}$ Co-crystals with malonic acid (1:1), 5-chlorosalicylic acid (1:2) and anthranilic acid (1:1) exhibit acidimidazole heterosynthon, except gallic acid co-crystal dihydrate $(1: 1: 2)$ in which the water molecule acts as a competitor and forms water-imidazole hydrogen bond. Further, the acid-amide heterosynthon is observed in all the co-crystals except anthranilic acid co-crystal (1:1) in which amide-amide dimer in theobromine is observed.

\subsection{Powder X-ray diffraction}

Powder x-ray diffraction is an accurate characterization technique for the identification of new solid forms (co-crystal, salt, hydrate and solvate) of a drug at 


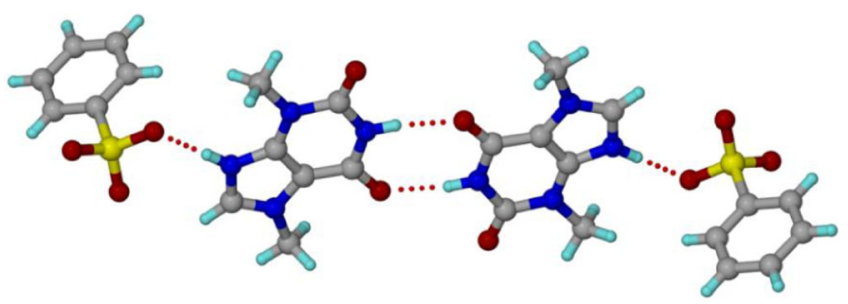

(a)

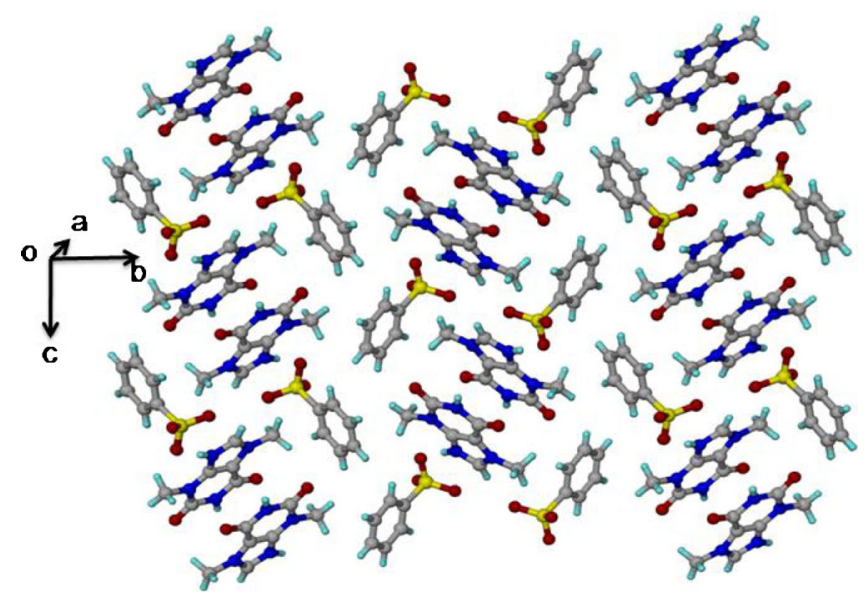

(b)

Figure 6. (a) $\mathrm{TBRH}^{+}$carboxamide dimer and $\mathrm{N}^{+}-\mathrm{H} \cdots$ $\mathrm{O}^{-}$hydrogen bond in the crystal structure of $\mathrm{TBRH}^{+} \mathrm{BES}^{-}$. (b) Packing diagram of the salt.

a precision of $\Delta 2 \theta> \pm 0.2^{\circ}$. The commercial material is the stable form of TBR as confirmed by its PXRD overlay with the reported crystal structure. ${ }^{9}$ There is no sign of any phase change (such as to a hydrate form as for CAF/TPH) even after storage for 1 year at ambient conditions. The new salts were confirmed from their signature PXRD patterns and compared with the calculated X-ray diffraction line patterns of the corresponding crystal structures (figure S1). We were unable to reproduce the mesylate (form I) and phosphate (1:3) salt for complete characterization.

\subsection{Thermal stability of theobromine salts}

New solid forms can be confirmed from the melting endotherm, which is different from the pure components by differential scanning calorimetry (DSC). Commercial TBR exhibits onset of the melt endotherm at $347^{\circ} \mathrm{C}$ and other the salts dissociate to TBR after melting as indicated by a broad peak in the temperature range of $330-350^{\circ} \mathrm{C}$ (figure 8). $\mathrm{TBRH}^{+} \mathrm{Cl}^{-}$(M.p. $\left.165^{\circ} \mathrm{C}\right)$, TBR.PHP $\left(1: 2.5\right.$, M.p. $\left.170^{\circ} \mathrm{C}\right)$ and $\mathrm{TBRH}^{+}$ $\mathrm{MES}^{-}$form II (M.p. $216^{\circ} \mathrm{C}$ ) showed a significantly lower M.p. compared to that of TBR, perhaps due to the liquid nature of the conformers; whereas $\mathrm{TBRH}^{+} \mathrm{BES}^{-}$ (M.p. $273^{\circ} \mathrm{C}$ ) and $\mathrm{TBRH}^{+} \mathrm{TOS}^{-}$(M.p. $284^{\circ} \mathrm{C}$ ) showed comparatively higher M.p. as BES and TOS are solid at ambient conditions. $\mathrm{TBRH}^{+} \mathrm{Cl}^{-}$hydrate releases one equivalent of water molecule at $120-140^{\circ} \mathrm{C}$ followed by melting at $165^{\circ} \mathrm{C}$. Because of their metastable nature, form I of $\mathrm{TBRH}^{+} \mathrm{MES}^{-}$and $\mathrm{TBRH}^{+} \mathrm{PHP}^{-3}$ salts were not reproducible to perform DSC experiments.

\subsection{FT-IR spectroscopy}

Infrared spectroscopy ${ }^{19}$ is a quantitative tool for the characterization and identification of salts from the cocrystals or polymorphs. The IR band at 3114 and 3156 $\mathrm{cm}^{-1}$ are allotted due to pyrimidine ring NH of TBR. Two carbonyl group vibrations in the meta position at 1658 and $1567 \mathrm{~cm}^{-1}$ are considered to be due to $\mathrm{C}=\mathrm{O}$ asymmetric and symmetric stretching vibrations. TBR shows strong $\mathrm{C}=\mathrm{N}$ stretching vibration band at 1689 $\mathrm{cm}^{-1}$. In all the salts, there are characteristic doublets at around $1670-1720 \mathrm{~cm}^{-1}$ corresponds to protonated imidazole $\mathrm{C}=\mathrm{N}^{+}-\mathrm{H}$ and its resonance form in the salt structures(figure S2). Vibrational frequencies of TBR salts are summarized in table 3 .

\subsection{Solubility and stability study}

Dissolution rate and apparent solubility of solid forms are highly important in drug development. Quick dissolution and higher apparent solubility may increase in more absorption of a drug. TBR is less soluble (330 $\mathrm{mg} / \mathrm{L})$ compared to its close analogues CAF (21.6 g/L) and TPH $(7.4 \mathrm{~g} / \mathrm{L})$. To improve the aqueous solubility of TBR, pharmaceutical salts were prepared with stronger acids and their solubilities were determined and compared with that of TBR. Solubility experiments in distilled water showed that all the salts dissociated to TBR after $1 \mathrm{~h}$ (figure S3). This may be due to the high solubility differences between TBR and the coformer acids (incongruent systems) ${ }^{20}$ and also weakness of the salt structures due to the weak base TBR. The salts dissociated much faster compared to the co-crystals, ${ }^{7 \mathrm{a}-\mathrm{d}, \mathrm{f}}$ since the salts are generally more hygroscopic. Even though the salts dissociated after $1 \mathrm{~h}$, they showed 6-87 folds increase in the solubility of TBR, whereas the improvement in solubility of co-crystals was 3-6 folds only (table 4). Remarkably, besylate and tosylate salts exhibited 88 and 58 fold higher solubility (after $1 \mathrm{~h}$ dissociation to TBR) than TBR following the solubility of the coformer rule. ${ }^{21}$ 


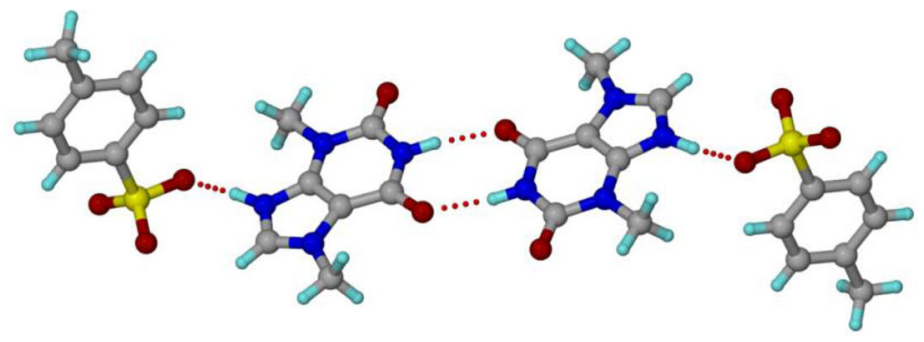

(a)

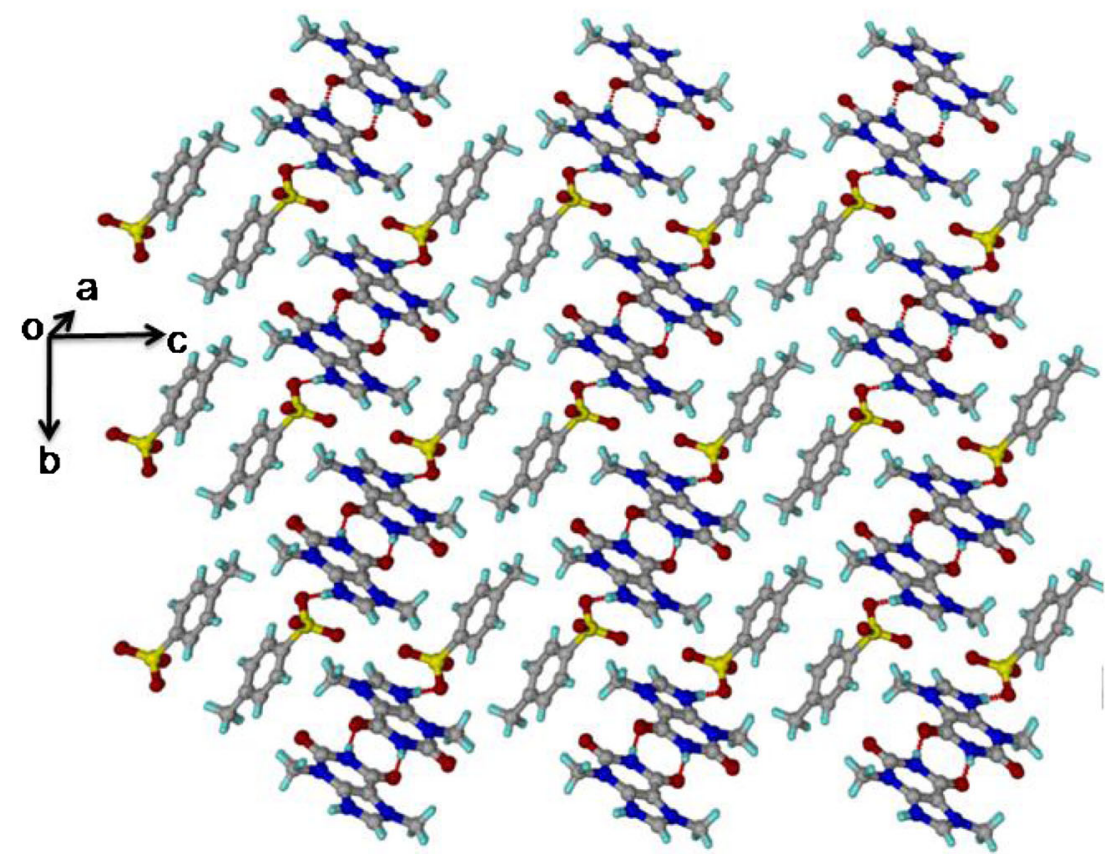

(b)

Figure 7. (a) $\mathrm{TBRH}^{+}$carboxamide dimer and $\mathrm{N}^{+}-\mathrm{H} \cdots \mathrm{O}^{-}$hydrogen bond between $\mathrm{TBR}^{+}$and $\mathrm{TOS}^{-}$. (b) Packing diagram $\mathrm{TBRH}^{+} \mathrm{TOS}^{-}$salt.<smiles>CC(=O)NC=O</smiles>

Amide-amide dimer<smiles>CC(=O)N(C)COCN(C)C(C)=O</smiles>

Amide-amide catemer<smiles>Cn1ccnc1</smiles>

Imidazole Hydrochloride

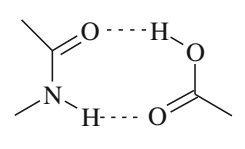

Amide-acid<smiles>Cn1ccnc1</smiles>
Imidazole phosphate<smiles>CC(=O)O[C@@H](C)C1=CC=[N+](C)C1</smiles>

Acid-imidazole<smiles></smiles>

Imidazole sulfate

Scheme 3. Homo- and heterosynthons observed in TBR cocrystals and salts. 
Table 2. Synthons observed in TBR salts of this paper as well as reported co-crystal structures.

\begin{tabular}{ll}
\hline Crystal structure & Synthon \\
\hline TBR & Amide-amide dimer \\
$\mathrm{TBRH}^{+} \mathrm{Cl}^{-}$ & Imidazole chloride \\
$\mathrm{TBRH}^{+} \mathrm{PHP}^{-} 3$ & Amide-amide \\
$\mathrm{TBR}^{+} \mathrm{PHP}^{-} 2.5$ & Amide-amide, Imidazole-phosphate \\
$\mathrm{TBRH}^{+} \mathrm{MES}^{-}$form I & Amide-amide dimer, Imidazole-sulfate \\
$\mathrm{TBRH}^{+} \mathrm{MES}^{-}$form II & Amide-amide catemer, Imidazole-sulfate \\
$\mathrm{TBRH}^{+} \mathrm{BES}^{-}$ & Amide-amide, Imidazole-sulfate \\
$\mathrm{TBRH}^{+} \mathrm{TOS}^{-}$ & Amide-amide, Imidazole-sulfate \\
$\mathrm{TBR}^{-}$malonic acid & Acid-amide and acid-imidazole \\
TBR-gallic acid. $2 \mathrm{H}_{2} \mathrm{O}^{\mathrm{a}}$ & Acid-amide, imidazole-water \\
TBR-5-chlorosalicylic acid & Acid-amide and acid-imidazole \\
TBR-anthranilic acid & amide-amide dimer and acid-imidazole heterosynthons
\end{tabular}

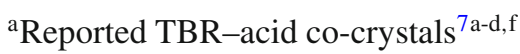

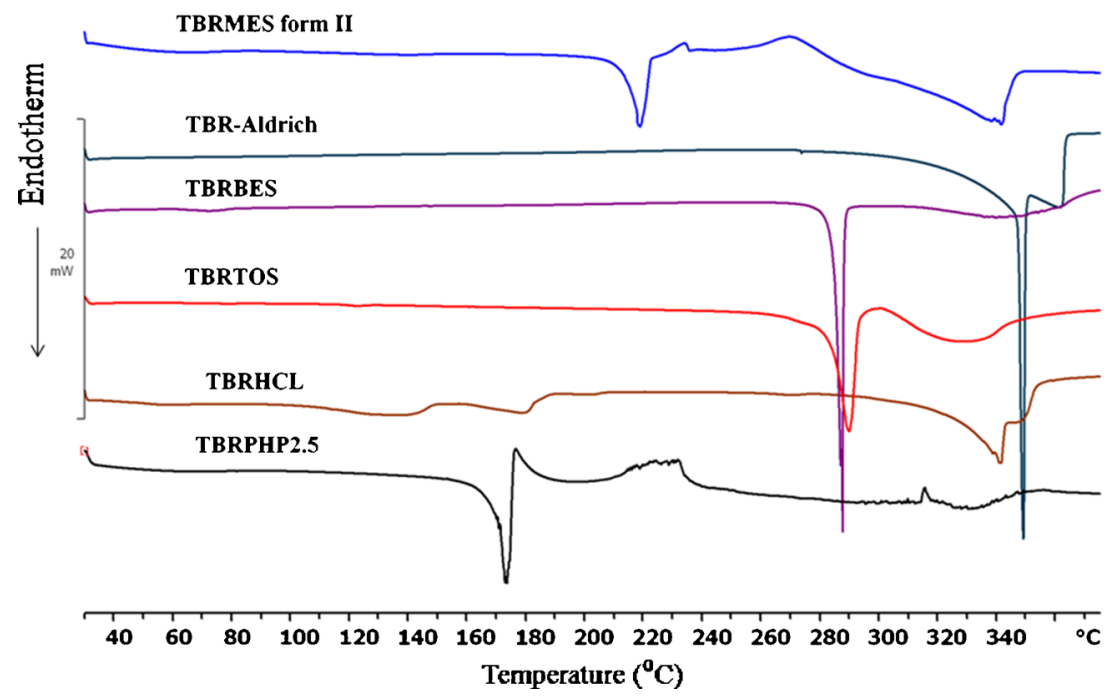

Figure 8. DSC endotherm of TBR salts indicating dissociation to theobromine after melting.

Table 3. FT-IR vibrational frequencies $\left(\mathrm{cm}^{-1}\right)$ of theobromine salts.

\begin{tabular}{lcccc}
\hline & N-H stretch & C=N stretch & C=O stretch & C-N stretch \\
\hline TBR & $3156.6,3114.4$ & 1689.4 & $1658.2,1547.9$ & 1139.6 \\
$\mathrm{TBRH}^{+} \mathrm{Cl}^{-}$ & $3165.1,3113.8$ & $1712.2,1694.0$ & 1549.0 & $1155.5,1131.4$ \\
$\mathrm{TBRH}^{+} \mathrm{PHP}^{-} 2.5$ & 3176.6 & $1724.4,1676.1$ & 1558.1 & $1158.3,1141.8$ \\
$\mathrm{TBRH}^{+} \mathrm{MES}^{-}$form II & $3180.0,3121.5$ & $1726.8,1697.7$ & 1548.0 & 1160.0 \\
TBRH $^{+}$BES $^{-}$ & $3156.6,3123.1$ & $1719.4,1704.6$ & 1546.3 & $1145.7,1123.2$ \\
TBRH $^{+}$TOS $^{-}$ & 3163.1 & $1721.3,1703.6$ & 1548.4 & $1147.8,1132.3,1122.3$ \\
\hline
\end{tabular}


Table 4. Solubility of theobromine salts and cocrystals in water. The increase relative to TBR is shown in parenthesis.

\begin{tabular}{|c|c|c|c|c|c|}
\hline & $\begin{array}{c}\text { Absorption } \\
\text { coefficient, } \\
\varepsilon, \mathbf{m M}^{-1} \mathbf{c m}^{-1}\end{array}$ & $\begin{array}{c}\text { Aqueous } \\
\text { solubility } \\
(\mathrm{mg} / \mathrm{L}) \text { at } 1 \mathrm{~h}\end{array}$ & $\begin{array}{l}\text { Aqueous } \\
\text { solubility of the } \\
\text { coformers }(\mathrm{g} / \mathrm{L})\end{array}$ & $\begin{array}{l}\text { Residue after } \\
\text { slurry for } 1 \mathrm{~h}\end{array}$ & Density $\left(\mathrm{g} \mathrm{cm}^{-3}\right)$ \\
\hline TBR & 25.38 & 316.7 & - & TBR & 1.524 \\
\hline TBR-malonic acid ${ }^{\mathrm{a}}$ & 8.68 & $1537.2(\times 4.9)$ & 763 & TBR & 1.533 \\
\hline TBR-gallic acid. $2 \mathrm{H}_{2} \mathrm{O}^{\mathrm{a}}$ & 17.84 & $1035.6(\times 3.3)$ & 12.0 & TBR-gallic acid. $2 \mathrm{H}_{2} \mathrm{O}$ & 1.603 \\
\hline TBR-5-chlorosalicylic acid ${ }^{\mathrm{a}}$ & 10.65 & $1855.7(\times 5.9)$ & 1.0 & TBR-5-chlorosalicylic acid & 1.572 \\
\hline TBR-anthranilic acid ${ }^{\mathrm{a}}$ & 11.23 & $1374.0(\times 4.3)$ & 5.7 & TBR-anthranilic acid & 1.546 \\
\hline $\mathrm{TBRH}^{+} \mathrm{Cl}^{-} \cdot \mathrm{H}_{2} \mathrm{O}$ & 24.47 & $2130.9(\times 6.7)$ & Miscible & TBR & 1.531 \\
\hline $\mathrm{TBRH}^{+}-\mathrm{MES}^{-}$form II & 21.38 & $2022.7(\times 6.4)$ & Miscible & TBR & 1.611 \\
\hline $\mathrm{TBRH}^{+}-\mathrm{BES}^{-}$ & 30.31 & $27737.2(\times 87.6)$ & 930 & $\begin{array}{l}\sim 11 \% \text { TBRTOS }+ \\
\sim 89 \% \text { TBR }\end{array}$ & 1.559 \\
\hline $\mathrm{TBRH}^{+}-\mathrm{TOS}^{-}$ & 29.16 & $18237.6(\times 57.6)$ & 670 & TBR & 1.534 \\
\hline $\mathrm{TBR}^{+}(\mathrm{PHP})_{3}^{-}$ & 21.94 & $6975.4(\times 22.0)$ & Miscible & $\begin{array}{l}\sim 29 \% \text { TBRPHP }+ \\
\sim 71 \% \text { TBR }\end{array}$ & 1.780 \\
\hline
\end{tabular}

${ }^{\text {a }}$ see ref. ${ }^{7 \mathrm{a}-\mathrm{d}, \mathrm{f}}$ for reported TBR-acid cocrystals.

Water mediated phase transformation ${ }^{5}$ may occur in three steps: dissolution of salts (or co-crystals) to create a supersaturated solution (high increase in solubility) followed by nucleation of the less soluble phase (here TBR) and the growth of that crystalline phase. When the growth of the less soluble phase occurs on the surface of the metastable solid (here co-crystal/salt), this phenomenon can cause a marked decrease in dissolution rate during in vitro dissolution evaluation, and ultimately in vivo. Therefore, transformation to a less soluble solid during dissolution is an important aspect to consider when evaluating approaches to increase the solubility of poorly soluble drugs. Considering the co-crystal structures, both malonic acid (unstable in aqueous medium) and 5-chlorosalicylic acid (stable) co-crystals have acidamide and acid-imidazole heterosynthons (table 2). It is difficult to explain the difference in their dissociation behavior in the aqueous medium. The anthranilic acid co-crystal has amide-amide homosynthon, similar to TBR, but it is stable in the aqueous environment. Among the four co-crystals considered here, TBRmalonic co-crystal has the least density (table 4), which may correlate with its low stability in the aqueous medium.

Generally, water miscible solid/liquid coformers dissociate faster from the salt than less soluble ones. The TBR co-crystals with 5-chlorosalicylic acid, ${ }^{7 \mathrm{a}}$ gallic acid (dihydrate) ${ }^{7 \mathrm{~d}}$ and anthranilic acid $^{7 \mathrm{f}}$ were stable at $24 \mathrm{~h}$ slurry experiments in our hands, but the malonic co-crystal ${ }^{7 \mathrm{~b}}$ transformed to TBR within $1 \mathrm{~h}$. This may be explained on the basis of solubility difference between TBR and the coformer. Malonic acid is a highly soluble $(763 \mathrm{~g} / \mathrm{L})$ diacid, due to its enol tautomer and intramolecular H-bonding, which forms an incongruent system (co-crystal) with TBR and hence dissociation is fast in water (within $1 \mathrm{~h}$ ). In contrast, the relatively less soluble coformers such as gallic acid (12 g/L), 5-chlorosalicylic acid (1 g/L) and anthranilic acid $(5.7 \mathrm{~g} / \mathrm{L})$ form congruent systems with TBR and are stable in the aqueous medium (figure 9). TBR gallic acid co-crystal dihydrate is expected to be highly stable because two equivalents of water molecules stabilize the crystal lattice.

According to the US-FDA guidelines $(2013)^{22}$ on pharmaceutical co-crystals, the co-crystal must dissociate from the API before reaching the target site of action. Here, all the TBR co-crystals improved solubility by a mere 3-6 fold and are stable (except, TBR anthranilic acid) at more than $24 \mathrm{~h}$ in the aqueous medium. The salts however dissociated to the API within $1 \mathrm{~h}$ but on the positive side exhibited much higher solubility (20-90 times).

\section{Conclusions}

Even though CAF and TPH face a hydration problem in the crystalline form, closely related TBR shows little tendency for hydration. However, TBR solubility is very low and to address this issue, salts and co-crystals were prepared. A phosphate salt (1:2.5) was crystallized as the thermodynamic phase from the metastable (1:3) phosphate salt during crystallization. The dimer/catemer synthons of $\mathrm{TBR}^{+}$exhibit a rare example of hydrogen bonding differences in the mesylate salt. Solubility studies showed that the novel salts are more soluble than the reported co-crystals in 


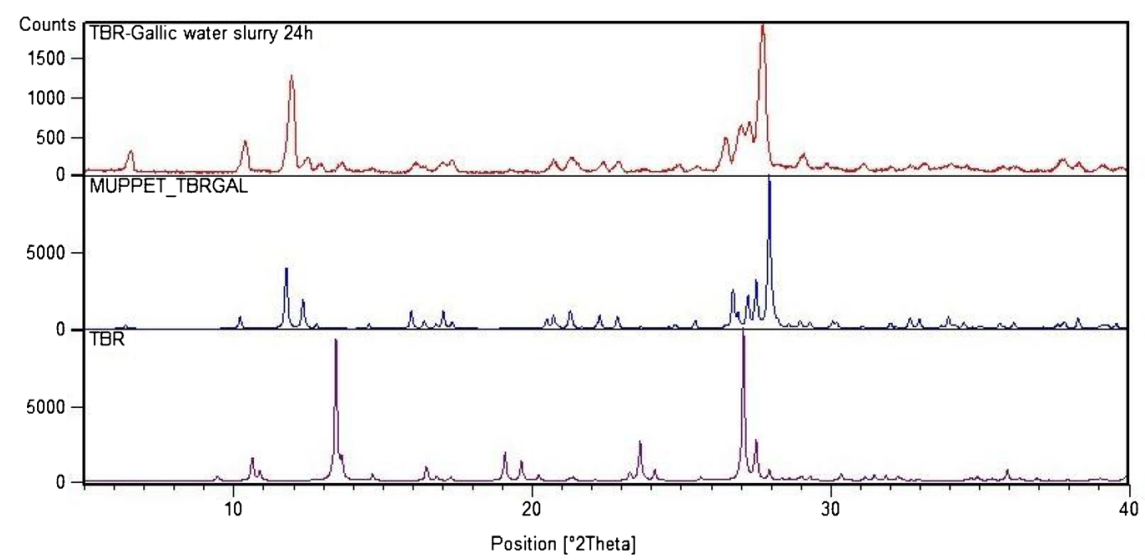

(a)

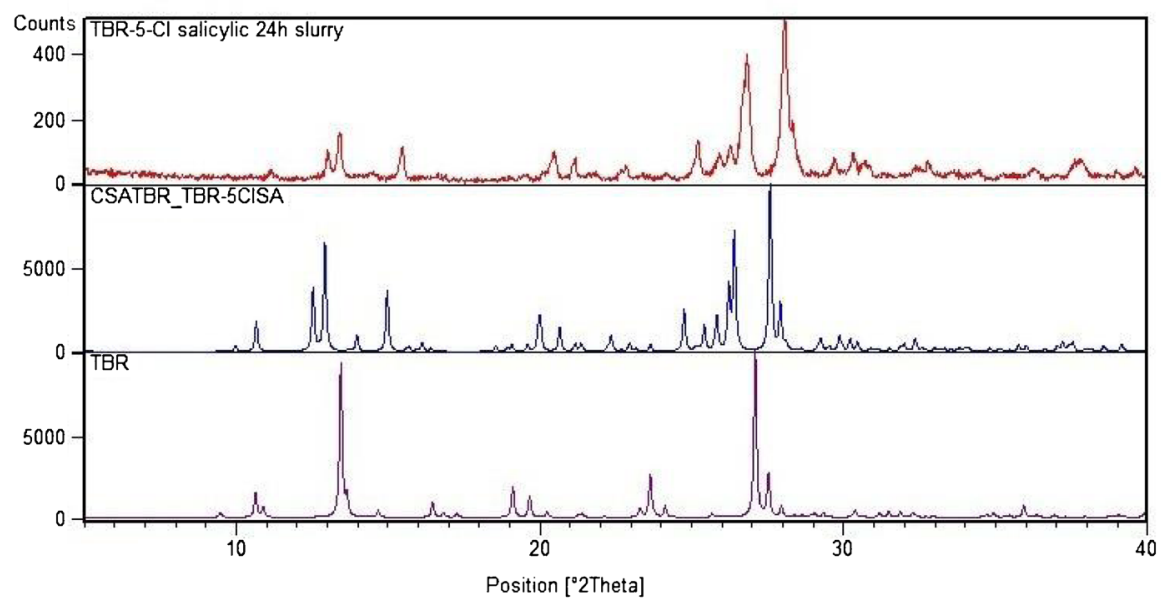

(b)

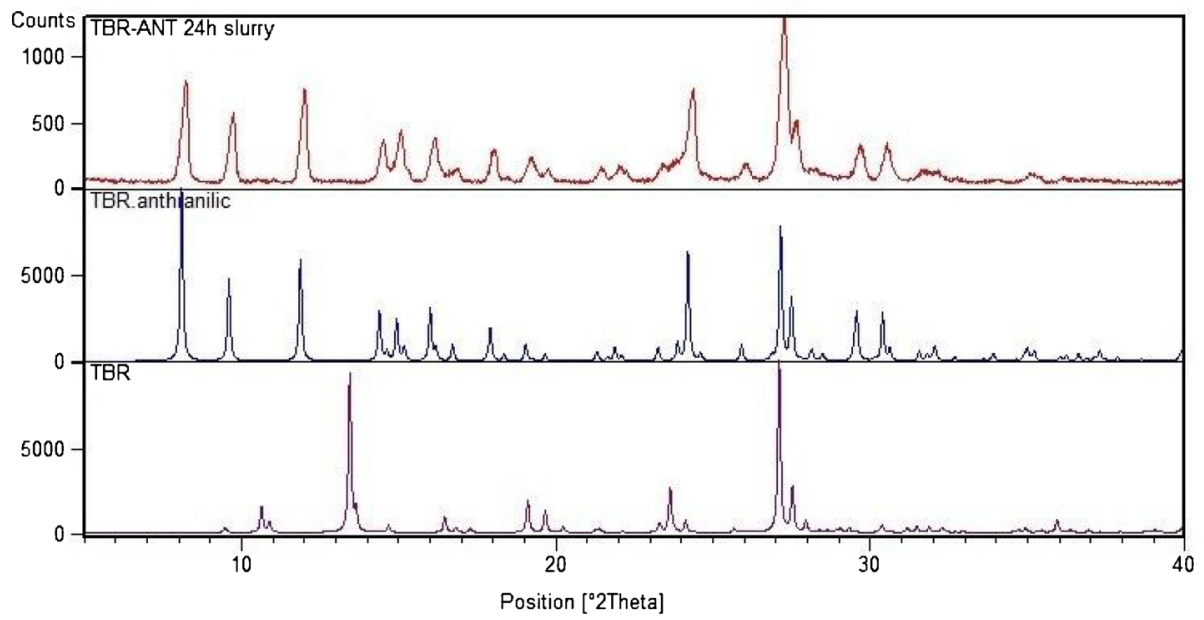

(c)

Figure 9. PXRD of TBR cocrystals with (a) gallic acid (dihydrate), (b) 5chlorosalicylic acid, and (c) anthranilic acid along with the calculated X-ray diffraction peaks from the crystal structure. The excellent peak-to-peak match indicates that the co-crystals are stable after $24 \mathrm{~h}$ in the aqueous slurry medium.

aqueous medium because of congruent systems (the only exception being the malonic acid co-crystal). The instability of TBR salts is due to solvent mediated phase transformation and the high solubility difference between TBR and the coformer acids. The besylate salt of TBR is the fastest dissolving form, but its instability 
is a setback. Further work will be carried out to improve the stability of the high soluble salts by excipients and additives.

\section{Supporting Information}

Crystallographic .cif files (CCDC Nos. 10191981019204) are available at www.ccdc.cam.ac.uk/data request/cif or as part of the Supporting Information. Normalized $\mathrm{H}$ bond table, IR and PXRD plots, and crystallographic .cif files are available http://www.ias. ac.in/chemsci/index.html.

\section{Acknowledgements}

PS thanks the UGC for a fellowship. We thank DST-SERB JC Bose fellowship (SR/S2/JCB-06/2009), SERB scheme Novel solid-state forms of APIs (SR/S1/OC-37/2011), and CSIR Project Pharmaceutical Cocrystals (01-2410/10/EMR-II). DST (IRPHA) and UGC (PURSE grant) are thanked for providing instrumentation and infrastructure facilities.

\section{References}

1. (a) Byrn S R, Pfeiffer R R and Stowell J G 1999 In Solid-State Chemistry of Drugs 2nd ed. (Indiana: SSCI Inc.); (b) Lipinski C 2002 Am. Pharm. Rev. 5 82; (c) Vippagunta S R, Brittain H G and Grant D J W 2001 Adv. Drug Delivery Rev. 48 3; (d) Babu N J and Nangia A 2011 Cryst. Growth Des. 112662

2. (a) Yalkowsky S 1999 In Solubility and Solubilization in Aqueous Media (Washington DC: American Chemical Society); (b) Chemburkar S R, Bauer J, Deming K, Spiwek H, Patel K, Morris J, Henry R, Spanton S, Dziki W, Porter W, Quick J, Bauer P, Donaubauer J, Narayanan B A, Soldani M, McFarland D and McFarland K 2000 Org. Process Res. Dev. 4 413; (c) Saharan V A, Kukkar V, Kataria M, Gera M and Choudhury P K 1999 Int. J. Health Res 2 107; (d) Sanphui P, Bolla G, Nangia A and Chernyshev V V 2014 IUCRJ 1136

3. (a) Berge S M, Bighley L D and Monkhouse D C 1977 J. Pharm. Sci. 66 1; (b) Prohotsky D L and Zhao F 2012 J. Pharm. Sci. 1011

4. (a) Stahl P H and Wermuth C G 2002 In Handbook of pharmaceutical salts: Properties, selection and use (Weinheim: Wiley-VCH); (b) Serajuddin A T M 2007 Adv. Drug Del. (Rev.) 59 603; (b) Sarveya V, Templeton J F and Benson H A E 2004 J. Pharm. Pharmacol. 56 717; (c) Kim S, Lee H and Kwan E 2008 Clin. Pharmacol. Therap. 83 S59; (d) Davies G 2001 Pharm. J. 266322 ; (e) Sarma B, Thakuria R, Nath K and Nangia A 2011 Cryst. Eng. Comm. 13 3232; (f) Bolla G and Nangia A 2012 Cryst. Growth Des. 126250
5. (a) Cardew P T and Davey R J 1985 Proc. R. Soc. Lond. A 398 415; (b) Greco K and Bogner R 2012 J. Pharm Sci.101 2996

6. (a) http://www.xocoatl.org/science.htm (accessed on 2 August, 2014); (b) Usmani O S, Belvisi M G, Patel H J, Crispino N, Birrell M A, Korbonits M, Korbonits D and Barnes P J 2005 The FASEB Journal 19 231; (c) Scheindlin S 2007 Mol. Interv. 7 236; (d) Lee H J, Lee K W, Kang K S, Kim D Y, Park H H, Lee M J, Kim H S and Kwon I B US patent 2003/0099686A1 May 2003; (e) Griesser U J and Burger A 1995 Int. J. Pharm. 120 83; (f) de Smidt J H, Fokkens J G, Grijseels H and Crommelin D J 1986 J Pharm Sci. 75497

7. (a) Shefter E, Brennan T F and Sackman P 1971 Chem. Pharm. Bull. 19 746; (b) Karki S, Fábián L, Friščić T and Jones 2007 W. Org. lett. 9 3133; (c) Cruz-Cabeza A J, Karki S, Fábián L, Friščić T, Day G M and Jones W 2010 Chem. Commun. 46 2224; (d) Clarke H D, Arora K K, Bass H, Kavuru P, Ong T T, Pujari T, Wojtas L and Zaworotko M J 2010 Cryst. Growth Des. 10 2152; (e) Biradha K, Samai S, Maity A C and Goswami S 2010 Cryst. Growth Des. 10 937; (f) Madusanka N, Eddleston M D, Arhangelskis M and Jones W 2014 Acta Crystallogr. B Struct. Sci. Cryst. Eng. Mater. 7072

8. (a) Rajput L, Sanphui P and Desiraju G R 2013 Cryst. Growth Des. 13 3681; (b) Goud N R, Suresh K and Nangia A 2013 Cryst. Growth Des 131590

9. Ford K A, Ebisuzaki Y and Boyle P D 1998 Acta Crystallogr., Sect. C 541980

10. (a) Derollez P, Correia N T, Danede F, Capet F, Affouard F, Lefebvre J and Descamps M 2005 Acta Cryst. C. 61 329; (b) Lehmann C W and Stowasser F 2007 Chem. Eur. J. 13 2908; (c) Enright G D, Terskikh V V, Brouwer D H and Ripmeester J A 2007 Cryst. Growth Des. 7 1406; (d) Ebisuzaki Y, Boyle P D and Smith J A 1997 Acta Cryst. C 53 777; (e) Zhang S and Fischer A 2011 Acta Cryst. E 67 o3357; (f) Khamar D, Pritchard R G, Bradshaw I J, Hutcheon G A and Seton L 2011 Acta Cryst. C 67 o496; (g) Fucke K, McIntyre G J, Wilkinson C, Henry M, Howard J A K and Steed J W 2012 Cryst. Growth Des. 121395

11. (a) Steed J W 2003 CrystEngComm. 5 169; (b) Desiraju G R 2007 CrystEngComm. 9 91; (c) Roy S, Banerjee R, Nangia A and Kruger G J 2006 Chem. Eur. J. 12 3777; (d) Babu N J, Reddy L S, Aitipamula S and Nangia A 2008 Chem. Asian J. 31122

12. Dunitz J D and Bernstein J. 1995 Acc. Chem. Res. 28 193

13. (a) Ostwald W 1879 Z. physik. Chem. 22 289; (b) Nývlt J 1995 Cryst. Res. Technol. 30443

14. (a) Ma L Y Y, Camerman N, Swartzendruber J K, Jones N D and Camerman A 1987 Can. J. Chem. 65 256; (b) Jegorov A, Horak Z, Cejka J, Kratochvil B and Cisarova I 2003 Acta Crystallogr. 59 o575; (c) Zhu N, Johnson L, White J and Klein-Stevens C L 2002 Struct. Chem. 13 491; (d) Gratz S R, Zeller M, Mincey D W and Flurer C L 2009 J. Pharm. Biomed. Anal. 50 228; (e) Grillo D, Polla G and Vega D 2012 J. Pharm. Sci. 101541

15. Nath N K and Nangia A 2011 CrystEngComm. 1347

16. Nanubolu J B, Sridhar B, Ravikumar K, Sawant K D, Naik T A, Patkar L N, Cherukuvada S and Sreedhar B 2013 CrystEngComm 154448 
17. CSD version 5.35, November 2013, Feb 2014 update, www.ccdc.cam.ac.uk

18. (a) Etter C M 1990Acc. Chem. Res. 23120 (b) Aakery C B, Epa K, Forbes S, Schultheiss N and Desper J 2013 Chem. Eur. J.19 14998

19. (a) Stuart B H 2004 In Infrared Spectroscopy: Fundamentals and Applications (UK: John-Wiley); (b) Gunasekaran S, Sankari G and Ponnusamy S 2005 Spectrochimica Acta Part A 61117

20. (a) Friščić* T, Childs S L, Rizvi S A A and Jones W 2009 CrystEngComm. 11 418; (b) Alhalaweh A and Velaga S P 2010 Cryst. Growth Des.10 3302; (c) Rodríguez-Hornedo N, Nehm S J, Seefeldt K F, Pagán-Torres Y and Falkiewicz C J 2006 Mol. Pharmaceutics 3 362; (d) Goud N R, Gangavaram S, Suresh K, Pal S, Manjunatha N G, Nambiar S and Nangia A 2012 J. Pharm. Sci. 101664

21. (a) Good D J and Rodríguez-Hornedo N 2009 Cryst. Growth Des. 9 2252; (b) Sanphui P, Tothadi S, Ganguly S and Desiraju G R 2013 Mol. Pharmaceutics 104687
22. US-FDA guideline on pharmaceutical cocrystals (2013). http://www.fda.gov/Drugs/GuidanceComplianceRegula toryInformation/Guidances/default.htm

23. CrysAlis CCD and CrysAlis RED Ver. 1.171.33.55, Oxford Diffraction Ltd., Yarnton Oxfordshire UK 2008

24. Dolomanov O V, Bourhis L J, Gildea R J, Howard J A K and Puschmann H 2009 J. Appl. Crystallogr. 42 339

25. SMART, Ver. 5.625 and SHELX-TL, Ver. 6.12; BrukerAXS Inc., Madison, Wisconsin, USA, 2000

26. (a) Spek A L 2002 In PLATON: A Multipurpose Crystallographic Tool (Utrecht University: Netherlands); (b) Spek A L 2003 J. Appl. Crystallogr. 367

27. Barbour L J 1999 In X-Seed, Graphical Interface to SHELX-97 and POV-Ray, Program for Better Quality of Crystallographic Figures (University of MissouriColumbia: USA)

28. Kraus N and Nolze G 2000 Powder Cell, Ver. 2.3, A Program For Structure Visualization, Powder Pattern Calculation and Profile Fitting, Federal Institute for Materials Research and Testing. Berlin, Germany 